\title{
Continuous GPS measurements of contemporary deformation across the northern Basin and Range province
}

\author{
R. A. Bennett, ${ }^{1}$ B. P. Wernicke, ${ }^{2}$ and J. L. Davis ${ }^{1}$
}

\begin{abstract}
We have acquired and analyzed data from the northern Basin and Range (NBAR) continuous GPS network since July 1996. The RMS residual with respect to the best fitting lines through the individual station position estimates is $2-3 \mathrm{~mm}$ in the horizontal and 6-10 $\mathrm{mm}$ in the vertical. After the first 395 days of operation, uncertainties in horizontal velocity estimates are $1-2 \mathrm{~mm} / \mathrm{yr}(1-\sigma)$. Relative motion among NBAR sites located in eastern Nevada and in Utah is small, but east-west extension is significant assuming uniform strain accumulation across the whole network. The relative motion observed across the Wasatch fault zone is $2 \pm 2 \mathrm{~mm} / \mathrm{yr}$, east-west. Relative motions among stations in western Nevada and California, in contrast, are dominated by northwest, right-lateral shear. We infer an integrated deformation across the northern Basin and Range of $11 \pm 2 \mathrm{~mm} / \mathrm{yr}$, northwest. These rates are consistent with previous geodetic measurements. Our GPS velocity estimates, however, reveal a possibly abrupt transition from east-west extension in eastern Nevada and Utah to right-lateral shear in western Nevada. This transition is roughly coincident with the central Nevada seismic belt and is consistent with the right-oblique focal mechanisms of the 1954 Dixie Valley and Fairview Peak earthquakes. The transition also appears to correlate spatially with a transition in upper mantle structure.
\end{abstract}

\section{Introduction}

The boundaries of oceanic plates are generally defined by narrow belts of seismicity with widths of a few tens of kilometers. In contrast, plate boundaries within the continental lithosphere are often expressed as broad zones of deformation with widths of hundreds to thousands of kilometers [e.g., lsacks et al., 1968]. Rigid plate motion models do not satisfactorily explain the complex kinematics of these continental deformation zones. Seismological and geological observations, moreover, reveal considerably different views of continental plate boundary behavior. Geological observations, pertaining to time scales of thousands to millions of years, indicate that large scale continental deformations are rather uniformly distributed over hundreds to thousands of kilometers [e.g., England and McKenzie, 1982]. Seismicity, representing contemporary strain release, appears to be localized into $10-100 \mathrm{~km}$ wide belts, inspiring the conception of "microplates" outlined by these belts [e.g., McKenzie, 1972; Smith, 1977].

\footnotetext{
${ }^{1}$ Harvard-Smithsonian Center for Astrophysics, Cambridge, MA

${ }^{2}$ California Institute of Technology, Pasadena, CA
}

Copyright 1998 by the Americen Geophynical Union.

Paper number 98GL00128.

0094-8534/98/98GL-00128\$05.00
Hence, a fundamental question is whether contemporary strain accumulation is localized within these belts, or whether the belts migrate across wider zones of more uniform strain accumulation. Although plate tectonic models representing non-radial motions of Earth's surface since $3 \mathrm{Ma}$ provide an estimate of the integrated rates of deformation across continental plate boundaries [e.g., Minster and Jordan, 1984], and very long baseline interferometry (VLBI) has provided a direct measure of contemporary, large scale plate tectonic motions [Argus and Gordon, 1991; Gordon et al., 1993], geodesy using the Global Positioning System (GPS) is the only technique capable of resolving the distribution of diffuse deformation within the continents at a reasonable cost.

The northern Basin and Range province of the western United States is a textbook example of diffuse continental deformation. Finite deformation since 5-10 Ma appears to be remarkably uniform, resulting in some 25 north-trending mountain ranges bounded by Quaternary normal faults, with relatively uniform spacing $(\sim 30 \mathrm{~km})$ and height above surrounding basins $(\sim 2000 \mathrm{~m})$. Historical seismicity, on the other hand, is concentrated into three roughly north-trending belts (Figure 1). Major historical earthquakes include the 1872 M7.2 Owens Valley, the 1915 M7.3 Pleasant Valley, the 1954 M7.1 Fairview

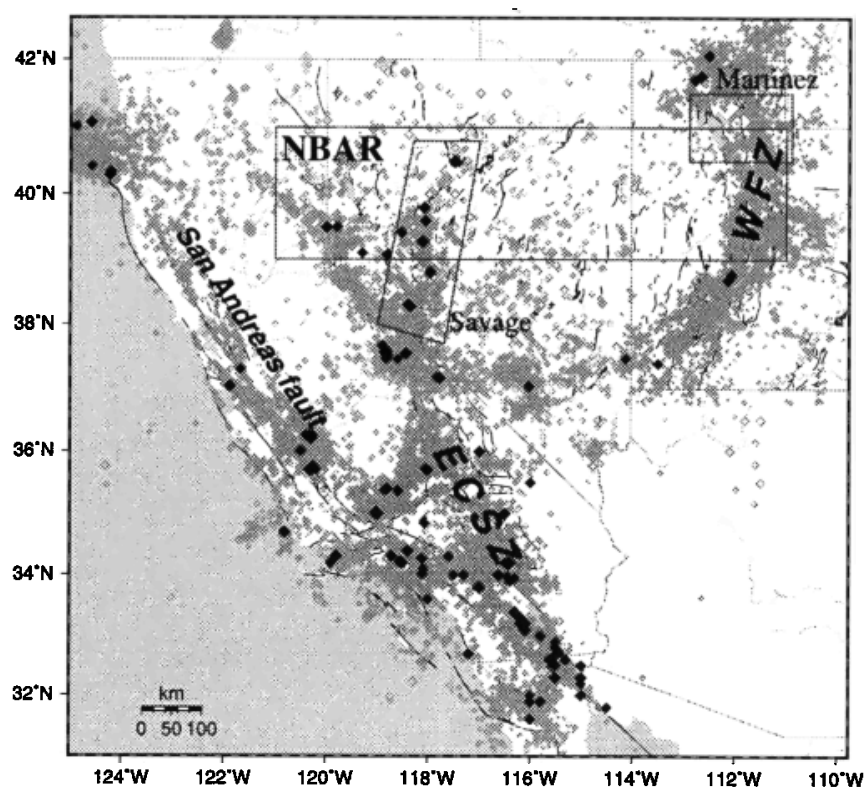

Figure 1. Location map of the southwestern U.S. showing seismicity over roughly the last 30 years (diamonds) and major fault zones (solid lines). The large black diamonds show $\mathrm{M}>6$ earthquakes. Boxes show the location of the northern Basin and Range (NBAR) continuous GPS network, the general location of the geodetic networks of Savage et al. [1995] and Martinez et al. [1998]. 
Peak, and the 1992 M7.4 Landers events. These events reveal a transition from north-northwest right-lateral slip, through right-oblique events, to east-west extension from west to east. Paleoseismological studies reveal a general pattern of seismicity "filling-in" at a given longitude on the time scale of 100-1000 years, with activity migrating from band to band on the time scale of 10,000-100,000 years [e.g., Wallace, 1984; 1987].

The northern Basin and Range (NBAR) continuous GPS network was devised to measure the scale and distribution of contemporary intraplate strain across diffusely deforming continental lithosphere. Below, we present the initial results from this network based on 13.5 months of continuous monitoring. These results bear on the problem of strain heterogeneity across the Basin and Range, and, perhaps more importantly at this stage, the capability of continuous GPS to resolve rates with high precision in a relatively short time.

\section{The NBAR GPS network}

Eighteen remote stations comprise the NBAR GPS network, spanning roughly $800 \mathrm{~km}$ from the Sierra Nevada in California to the Rocky Mountains in Utah (Figure 2). All sites consist of braced tripod monuments, deeply anchored $(>10 \mathrm{~m})$ in bedrock to minimize monument noise [e.g., Langbein et al., 1995]. Each site is equipped with either a Trimble SSi or SSE GPS receiver and choke-ring antenna. Radomes were installed in January 1997. All sites enjoy excellent sky visibility, and generally low levels of atmospheric water vapor. Power is provided by a combination of solar panels and deep-cycle batteries. The stations operate continuously, recording GPS observables every 30 seconds. Also recorded are the ambient temperature and other operating parameters. Communication methods include: radio modem to standard telephone modem link; cellular modem link; microwave modem link; and combined radio and microwave modem link. The download procedure for several sites involves an additional transfer across the Internet, facilitated by a workstation at the University of Nevada, Reno.

Automated downloads of 24 hour blocks of NBAR data are performed every night. The following data products are also downloaded every night from the Scripps Orbit and Permanent Array Center (SOPAC): precise orbits, raw International GPS Service (IGS) station data, and Earth orientation parameters.

Installation of the first eight of the NBAR stations was completed by August 1, 1996. Installation of the remaining 10 stations was completed as of July, 1997. Six of these latter sites do not yet have enough observations to estimate useful velocities. Therefore, in this paper, we concentrate on results from 12 of the stations, which represent the first $\mathbf{1 3 . 5}$ months of operation of the network.

\section{Data Analyses}

After download, an automated computer analysis system employing the GAMIT software package [King and Bock, 1995] processes all GPS data. This system produces sets of loosely determined geodetic parameter estimates, including station positions, satellite orbital parameters, and Earth orientation parameters. Each set represents one 24-hour period of observations.

These parameter estimate sets, together with their joint, uncollapsed covariance matrix, are combined with similarly loosely determined parameter estimates and associated covariance matrices from analyses of raw data from globally distributed GPS stations obtained from the SOPAC facility. Combination of these data is performed with the GLOBK Kalman filter [Herring, 1995]. The resulting combinations represent the positioning information contained in 24-hour periods of data from the NBAR, IGS, and several other regional GPS networks. There are nominally 166 continuous GPS stations represented in each combination presently. Because each of the respective parameter estimate sets share common Earth orientation and satellite orbit parameters, all parameter estimates, after combination, are in a common reference frame. Time series of these parameter estimate combinations, each representing a day's worth of GPS observations from stations around the globe are used to infer deformations of Earth.

To assess the quality of the site coordinate determinations from the first 13.5 months of the network's operation, we performed an analysis wherein we allowed the NBAR position estimates to vary freely from day to day, while tightly constraining the positions and coordinates of the primary IGS tracking stations to their ITRF94 values [Boucher et al., 1996]. The root-mean-square scatter

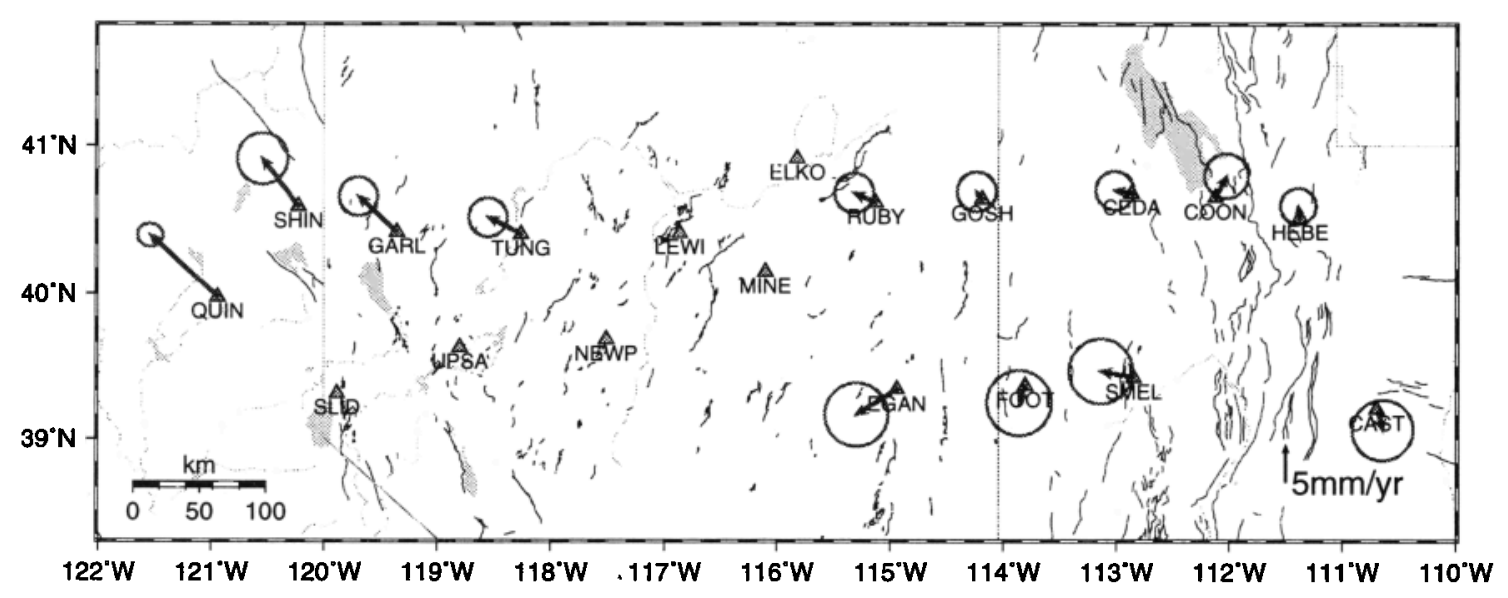

Figure 2. NBAR station locations and velocity estimates with respect to stable North America. Error ellipses represent the $95 \%$ confidence level. Site QUIN is part of the IGS network. We do not yet have accurate velocity estimates for all of the sites (see text). 


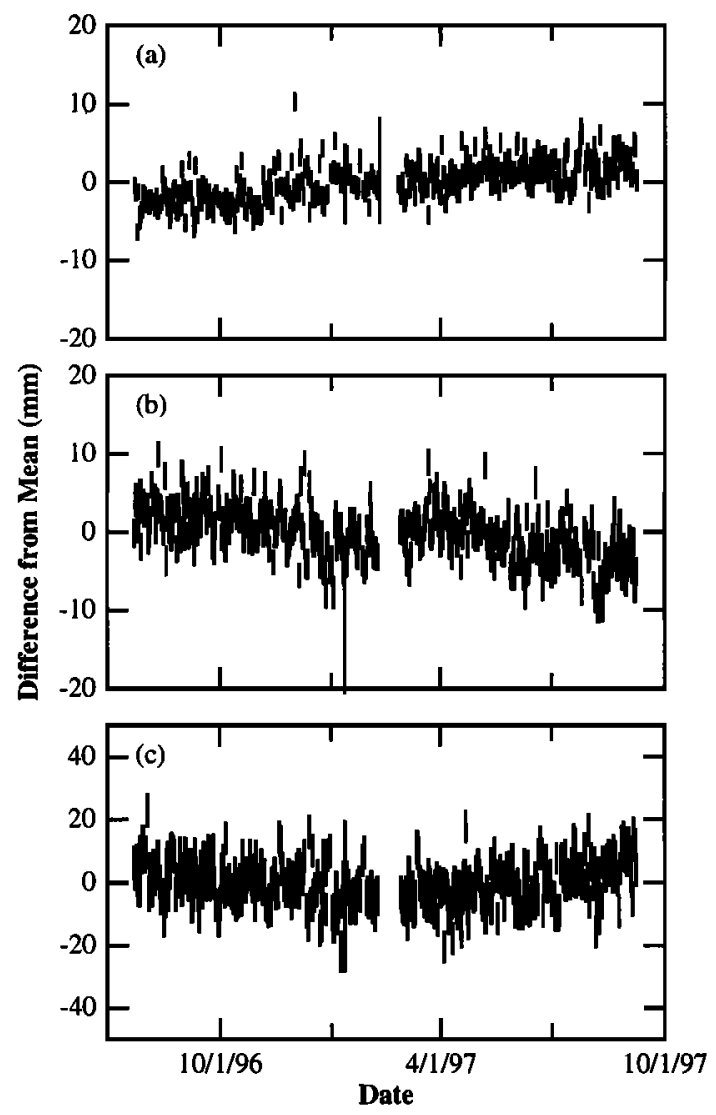

Figure 3. Time series of the estimated (a) north, (b) east, and (c) vertical (positive up) components for the GARL GPS site. The estimates are plotted relative to a mean position in a reference frame that is fixed with respect to North America. The estimated horizontal velocities are (a) $5 \pm 1 \mathrm{~mm} / \mathrm{yr}$ north and (b) $-5 \pm 1 \mathrm{~mm} / \mathrm{yr}$ east.

about the best-fit lines through the daily time series of site position estimates is $2-3 \mathrm{~mm}$ in the horizontal and 6-10 $\mathrm{mm}$ in vertical baseline components. A sample time series for site GARL is shown in Figure 3 in the North America fixed reference frame.

Spectral analyses of NBAR site position estimates indicate a slight reddening of the power spectrum. Cross correlations between position estimate variations reveal a peak correlation of 0.5 at zero days delay, indicating that $50 \%$ of the variance in the time series is attributable to common mode errors with no lag. Although common mode, such errors could contaminate constant, relative velocity estimates between station pairs with different lengths of data. Fortunately, most sites have similar spans of data and few data gaps, the exceptions being sites CAST, EGAN, FOOT, and SMEL (Figure 2) for which we presently have processed $<150$ days of data.

The NBAR site velocities that we estimated from the first 13.5 months of data are shown in Figure 2 in the North America fixed reference frame. We applied the same constraints on the primary IGS stations in estimating the velocities as for the time series analysis. To eliminate possible vertical errors from propagating into the horizontal estimates, particularly from those stations located $\sim 90^{\circ}$ away, we allowed the vertical components of all sites except the trackers to vary as independent random walks with large variances of $9 \mathrm{~mm}^{2} /$ day. We modeled the horizontal site velocities as constants in time.
The uncertainties in the horizontal components of the velocity estimates are in the range of $1-2 \mathrm{~mm} / \mathrm{yr}(1-\sigma)$.

\section{Results}

Our velocity estimates (Figure 2) reveal little relative motion among sites in eastern Nevada and Utah. However, right-lateral shear is apparent in western Nevada and California. We infer a rate of $2 \pm 2 \mathrm{~mm} / \mathrm{yr}$ between sites HEBE and CEDA straddling the Wasatch fault zone, consistent with the rate of $3 \pm 1 \mathrm{~mm} / \mathrm{yr}$ reported by Martinez et al. [1998]. We also infer a rate of $2 \pm 2 \mathrm{~mm} / \mathrm{yr}$ relative motion between sites RUBY and TUNG across central Nevada, consistent with the results of Savage et al. [1995]. Our rate estimates of $11 \pm 2 \mathrm{~mm} / \mathrm{yr}$ between sites HEBE and QUIN (spanning the breadth of the northern Basin and Range), and $9 \pm 2 \mathrm{~mm} / \mathrm{yr}$ between sites RUBY and QUIN (representing western Nevada and eastern California) are consistent with the results of Dixon et al. [1995] and are quite similar to the rates of 6-12 mm/yr measured across the eastern California shear zone [e.g., Sauber et al., 1994].

Figure 4 shows our velocity estimates projected onto an east-west trending profile through the center of the NBAR network. The east components of the velocities decrease fairly linearly from east to west across the network. The slope of the best fitting line through these east components is $10 \pm 1$ nstrain/yr, consistent with uniform east-west extension across the north trending normal faults spanned by the network.

The north components of the velocity estimates reveal a transition across the central Nevada region. Changes in the north components of the velocity estimates from east to west pertain to shear strains about the predominantly north trending faults zones. Our shear strain accumulation rate estimate of $2 \pm 3$ nstrain/yr, based on the north components of velocity for the easternmost stations in the NBAR network, reveals no statistically significant shear strain associated with the faults between sites HEBE and RUBY. The westernmost stations, on the other hand,

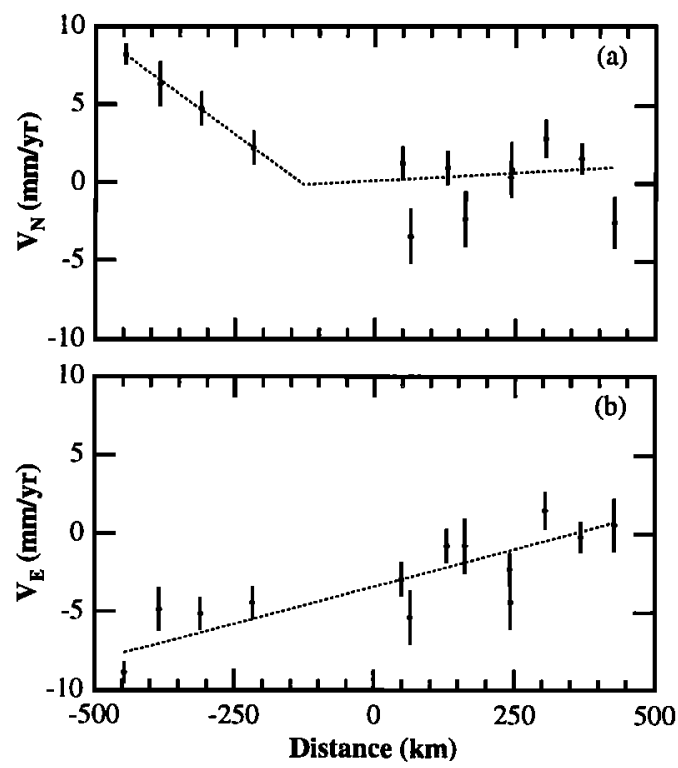

Figure 4. (a) North and (b) east components of the estimated velocities for the NBAR GPS sites plotted as a function of projected east-west distance. 
clearly exhibit distributed right-lateral shear at a rate of $26 \pm 5$ nstrain/yr.

Our GPS velocity estimates reveal two different regimes of deformation: an eastern extensional regime, and a western shear regime. Strain accumulation does not appear to be localized in the eastern extensional regime, in contrast to the highly concentrated band of seismicity associated with the Wasatch fault zone (Figure 1). This seismicity is highly correlated, however, with a transition in the effective elastic thickness, or equivalently the flexural rigidity, of the western U.S. lithosphere; effective elastic thickness is high east of the Wasatch fault zone and is very low west of this fault zone [Lowry and Smith, 1995]. To the extent that the effective elastic thickness provides a measure of the strength of the continental lithosphere, we suggest that this belt of seismicity reflects a transition zone between an actively deforming lithosphere with a relatively thin seismogenic layer to a very slowly deforming lithosphere with a thick seismogenic layer.

The western shear regime generally correlates with the belts of seismic strain release in central Nevada and eastern California (Figure 1). The transition zone between these regimes generally coincides with the location of the central Nevada seismic belt. This result is, in turn, consistent with the right-oblique focal mechanisms of the 1954 Dixie Valley and Fairview Peak earthquakes [e.g., Ellsworth, '1990].

These deformation regimes, furthermore, appear to correlate with inferred patterns in upper mantle structure [e.g., Humphreys and Dueker, 1994]; within $\sim 250 \mathrm{~km}$ of the California coast, upper mantle structures trend generally parallel to the northwest motions of the GPS sites; beneath much of the northern Basin and range province, upper mantle structures trend northeasterly. The transition zone between these two upper mantle domains coincides with the transition in crustal deformation that we observe.

Paleoseismological evidence suggests that episodes of seismic strain release associated with the faults in the vicinity of this transition may by clustered in time with activity migrating (longitudinally) from fault zone to fault zone [e.g., Wallace, 1984; 1987]. The relationship between the timing of these events, the transition in crustal deformation, and upper mantle processes, is presently not clear.

Acknowledgments. The University NAVSTAR Consortium (UNAVCO) facility assisted greatly in establishing the network. We thank the Seismological Laboratory at the University of Nevada, Reno, and particularly W. Nicks, for technical support and the University of Utah for assistance in site permitting. We also thank B. Frohring at Trimble Navigation Inc. who provided technical expertise. This manuscript benefited from careful reviews by J. Savage and an anonymous referee. We thank $\mathrm{R}$. Smith and C. Meertens for keeping us abreast of their related research. Figures 1 and 2 were produced with the GMT software. This project is supported by NSF Grants EAR 94-18784, EAR 95-12212, Trimble Navigation Inc., the California Institute of Technology, and the Smithsonian Institution.

\section{References}

Argus, D. F. and R. G. Gordon, Current Sierra-NevadaNorth America plate motion from very long baseline interferometry: Implications for the kinematics of the western United States, Geology, 19, 1085-1088, 1991.

Boucher, C., Z. Altamimi, M. Feissel, and P. Sillard, Results and analysis of the ITRF94, IERS Tech. Note 20, Technical report, Cent. Bur., Obs. de Paris, Paris, France, 1996.
Dixon, T. H., R. Stefano, J. Lee, and M. C. Reheis, Constraints on present-day Basin and Range deformation from space geodesy, Tectonics, 14, 755-772, 1995.

Ellsworth, W., Earthquake history, 1769-1989, U.S. Geol. Surv. Prof. Paper, 1515, 153-181, 1990.

England, P. and D. P. McKenzie, A thin viscous sheet model for continental deformation, Geophys. J. R. Astr. Soc., 70, 295-321, 1982.

Gordon, D., C. Ma, and J. W. Ryan, Results from the CDP mobile VLBI program in the western United States, in Contributions of space geodesy to geodynamics: Crustal dynamics, edited by Smith, D. E. and D. L. Turcotte, geodynamic series vol. 23, pp. 21-36, American Geophysical Union, Washington, 1993.

Herring, T. A., GLOBK: Global Kalman filter VLBI and GPS analysis program, Dept. Earth, Atmos., and Planet. Sci., Massachusetts Institute of Technology, Cambridge, Mass., 1995.

Humphreys, E. D. and K. G. Dueker, Physical state of the western U.S. upper mantle, Geophys. Res. Lett., 99, 96359650, 1994.

Isacks, B. L., J. Oliver, and L. Sykes, Seismology and the new global tectonics, J. Geophys. Res., 73, 5855-5900, 1968.

King, R. W. and Y. Bock, Documentation for the MIT GPS analysis software: GAMIT, Dept. Earth, Atmos., and Planet. Sci., Massachusetts Institute of Technology, Cambridge, Mass., 1995.

Langbein, J., F. Wyatt, H. Johnson, D. Hamann, and P. Zimmer, Improved stability of a deeply anchored geodetic monument for deformation monitoring, Geophys. Res. Lett., 22, 3533-3536, 1995.

Lowry, A. R. and R. B. Smith, Strength and rheology of the western U.S. Cordillera, J. Geophys. Res., 100, 17,94717,963, 1995.

Martinez, L., C. M. Meertens, and R. B. Smith, Rapid crustal deformation rates of the Wasatch fault, Utah, from first GPS measurements with implications for earthquake hazard, Geophys. Res. Lett., this issue, 1998.

McKenzie, D. P., Active tectonics of the Mediterranean region, Geophys. J. R. Astr. Soc., 30, 109-185, 1972.

Minster, J. B. and T. H. Jordan, Vector constraints on Quaternary deformation of the western United States east and west of the San Andreas fault, in Tectonics and Sedimentation along the California Margin, edited by Crouch, J. K. and S. B. Bachman, vol. 38, pp. 1-16, Pac. Sec. Soc. of Econ. Paleontol. and Mineral., Los Angeles, CA, 1984.

Sauber, J., W. Thatcher, S. Solomon, and M. Lisowski, Geodetic slip rate for the eastern California shear zone and the recurrence time of Mojave desert earthquakes, Nature, 367, 264-266, 1994.

Savage, J. C., M. Lisowski, J. L. Svarc, and K. K. Gross, Strain accumulation across the central Nevada seismic zone, J. Geophys. Res., 100, 20,257-20,269, 1995.

Smith, R. B., Intraplate tectonics of the western North American plate, Tectonics, 37, 323-336, 1977.

Wallace, R. E., Patterns and timing of late Quaternary faulting in the Great Basin province and relation to some regional tectonic features, J. Geophys. Res., 89, 5763-5769, 1984.

Wallace, R. E., Grouping and migration of surface faulting and variations in slip rates in faults in the Great Basin province, Bull. Seis. Soc. Am., 77, 868-876, 1987.

R. A. Bennett, J. L. Davis, Harvard-Smithsonian Center for Astrophysics, 60 Garden St, MS 42, Cambridge, MA, 02138 (e-mail: rbennett@cfa.harvard.edu)

B. P. Wernicke, California Institute of Technology, Pasadena, CA, 91125

(Received July 3, 1997; revised December 16, 1997; accepted December 30, 1997.) 